\title{
Prevalence of Anaemia and Nutritional Knowledge among Tribal Women of Reproductive Age Group of Meghalaya, India
}

\author{
Elvina Shongsir Monsang and Namita Singh* \\ Department of Food Science and Nutrition, College of Home Science, CAU (Imphal), Tura, \\ Meghalaya, India \\ *Corresponding author
}

\section{A B S T R A C T}

\section{Keywords}

Anaemia, Intake pattern, nutritional knowledge, nutritional practices,

Tribal women

Article Info

Accepted:

10 September 2018

Available Online:

10 October 2018
Anaemia is a major public health problem worldwide, mostly among females of reproductive age in developing countries. In India, the prevalence of anaemia among women of age group 15 to 49 years is much higher. The pattern of consumption plays a role in shaping the health of the people of a state. Food habits effect nutritional status therefore is necessary to assess the tribal food habits because a particular tribe food habits differ to another tribe and also from one region to another. A cross sectional study was conducted in five villages of three districts of Meghalaya among 150 randomly selected reproductive age group tribal women. Female with at least one child below 5 years of age was eligible to be study subjects. Haemoglobin concentration was checked by portable digital haemometer. Questionnaire on dietary pattern, nutritional knowledge and practices was developed and Personal interview method was used. The overall Mean \pm SD and prevalence of anaemia was $9.40 \pm 1.86 \mathrm{~g} / \mathrm{dl}$ and 92 per cent respectively. The study revealed that dietary pattern and nutritional knowledge and practices of the selected tribal women were not satisfactory up to the standard of living.

\section{Introduction}

Women constitute substantial population in any society and their statistics reflects the type of society and cultures they live in. Tribal women in India are at a great disadvantage due to illiteracy and ignorance (Ghosh, 2016).

Anaemia is a major public health problem worldwide, mostly among females of reproductive age in developing countries. In India, the prevalence of anaemia among women of age group 15 to 49 years is much higher. Lifestyle behaviour (smoking, alcohol drinking and chewing tobacco) has effects on anaemia levels among the women (Chauhan et al., 2015). WHO has estimated that, India has one of the highest prevalence of anaemia in the world. Anaemia is widely prevalent among tribal women of reproductive age group (1549 years) (Kamath et al., 2013). In India, anaemia is prevalent mostly among female sex of all age groups. Even those females with normal BMI were anaemic (Choudhary and Dashora, 2015). Most of the anaemic was in the age group of 20-40 years (Joshi et al., 2013). The pattern of consumption plays a role in shaping the health of the people of a state 
(Shadap and Pala, 2017). Food habits effect nutritional status therefore is necessary to assess the tribal food habits because a particular tribe food habits differ to another tribe and also from one region to another (Joshi and Singh, 2015). The common types of food consumed are rice, ragi and seasonal fruits and non-vegetarian (Nanda and Dhar, 2017). Nutritional knowledge of the tribal adult women was unsatisfactory and they need in-depth nutrition education and intervention programmes for their holistic development (Devi and Sindhuja, 2015).

In Meghalaya, chewing pan and raw areca nut is a common practice among both the sex resulting in higher number of pan chewers and tobacco users having negative impact in the health status. Majority are non-vegetarians, follow two meal patterns and do not have any food beliefs or taboos (Rynjah et al., 2009). Majority of the tribal are pan chewers, consumed alcohol and had smoking habits (Sreelakshmi et al., 2012). Meghalaya spends a lower percentage in the consumption of pulses and pulse products, milk and milk products and a higher percentage on egg, fish and meat, paan, supari, etc. (Shadap and Pala, 2017). Pan chewing is a socially accepted and widely prevalent habit among tribal women (Shrinivasa et al., 2014). Majority of the tribal community household are non-vegetarians, consumed two or three main meals daily, consumed packaged iodized salt and did not consume any milk or milk products (GhoshJerath et al., 2016). The intakes of green leafy vegetables, other vegetables, fruits, milk and milk products are low. The intake of all food groups except cereals, pulses and fats was deficient (Rao et al., 2006). Henceforth, the importance and necessity to study prevalence of anaemia, intake pattern, Nutritional knowledge and practices of tribal women of reproductive age group of Meghalaya was felt and in this backdrop, the present study was conducted with the following objectives;
To assess prevalence of anaemia among tribal women of reproductive age.

To study their nutritional knowledge and practices.

To know intake pattern of various foodstuff.

\section{Materials and Methods}

This research paper is a part of Post Graduate research conducted by the student before starting the data collection the study was presented in front of Institutional Ethical Committee (IEC) and ethical clearance was taken.

\section{Study area}

The area selected for the study is the state of Meghalaya of northeast India. The state is bounded by Assam in the north and by Bangladesh in the east, west and south. The state has a total area about 22,429 sq. Km. The following three districts of Meghalaya viz. West Garo Hills, Ri- Bhoi and West Jaintiya Hills districts were selected purposively for the study to cover three major tribal groups (Garo, Khasi and Jayantia) and easy accessibility of the researcher. The villages were selected by stratified random sampling technique.

\section{Units of study}

Women of reproductive age group i.e. 15-49 years were considered as unit of study. Female with at least one child below 5 years of age was eligible to be study subjects.

\section{Tools}

The primary tool in the study area was a predesigned and pretested interview schedule. The interview method is the only method, which enables the investigator to obtain the 
feelings of the respondents, and helps in getting first-hand information even from the illiterate. The haemoglobin concentration was checked by portable digital haemometer for all respondents by the researcher herself. Questionnaire on dietary pattern, nutritional knowledge and practices was developed by the researchers and Personal interview method was used by the researchers to obtain the relevant data on various aspects.

\section{Statistical techniques used}

For the data analysis, the collected data was entered in the computer and suitable tables were prepared with appropriate statistical analysis namely mean, S.D., frequency and percent were incorporated wherever necessary. The results of the study were given in the form of appropriate tables.

\section{Results and Discussion}

The research findings of the present study are discussed under the following heads:

\section{Anaemia}

Haemoglobin level was recorded to identify the prevalence of anaemia among the respondents. The cut-off haemoglobin level for adult women as per WHO is $<12 \mathrm{~g} / \mathrm{dl}$. Based on this cut-off point the subjects were categorised into mild, moderate and severe anaemia.

The overall prevalence of anaemia among the study tribal women was $92 \%$ with higher percentage in moderate anaemia (Fig. 1). The overall Mean \pm SD of anaemia was $9.40 \pm$ 1.86 g/dl. Similarly, Shrinivasa et al., (2014), Siddiqui et al., (2016) and Nanda and Dhar (2017) had reported higher percentage of anaemia prevalence in the reproductive age group. The prevalence of anaemia among the study tribal women had a higher percent in comparison to other tribes in India reported by Choudhary and Dashora (2015), Dabral and Kothiyal (2016), and Kaur and Kaur (2011).

\section{Nutritional knowledge and practices}

Knowledge of carbohydrate, fat, protein, iron, calcium, vitamins, balanced diet and five food groups and household practices like method of cooking, frequency of washing rice and dal, type of milk used, frequency of soda used, type of oil used, vegetable storage, boiled water, filtered water, likes and dislikes and food allergy were collected. The salient findings are given in table 1 and 2.

Not many of the subjects had knowledge about carbohydrates and fats, protein, iron, calcium and vitamins. Only 19.33 per cent, 17.33 percent, 21.33 per cent, 22 per cent and 15.33 per cent had knowledge of carbohydrate and fats, protein, iron, calcium and vitamins respectively. Filter water was used by 22.67 per cent and boiled water by 80.67 per cent. Mustard oil was consumed by 80.67 per cent. Majority $(73.33 \%$ and $74.67 \%)$ of them washed rice and dhal twice before cooking. All of them washed their vegetables and fruits before cutting. Iodised salt was used by all the subject.

All the subjects had two meals pattern. Majority $(80.67 \%)$ took tea twice a day. Open pan cooking method was used by 43.33 per cent and 70.67 per cent stored vegetables in opened space respectively. Food allergy especially chicken was found in 10.67 per cent. Cigarette smoking and alcohol consumption was not found among the respondent. All the respondents had the habit of chewing pan on a regular basis. The study subjects did not have any taboo or belief regarding food consumption. Balanced Diet and Five Food Groups knowledge was not known by the respondents. All the household were non-vegetarians. 


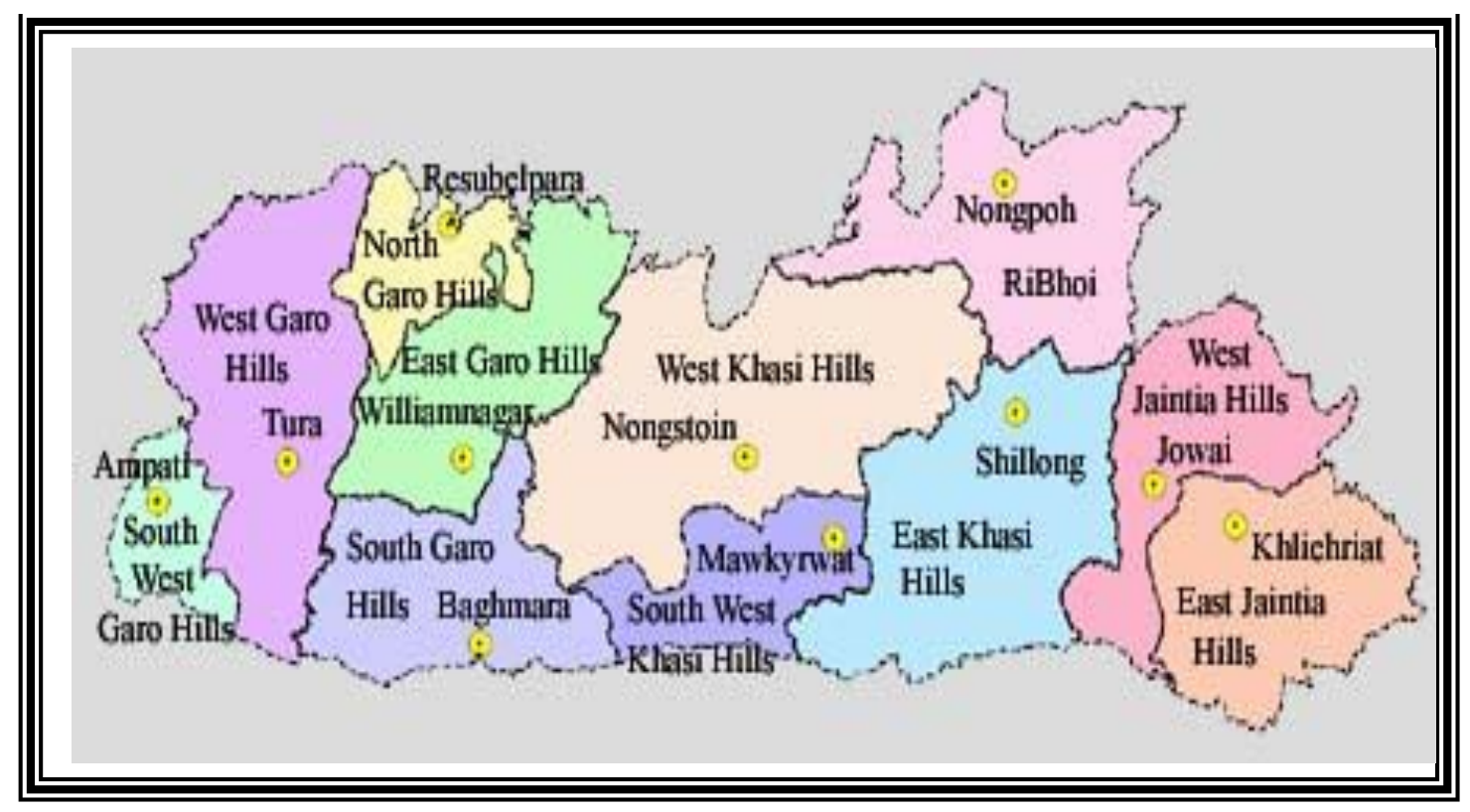

Fig. 1 District Map of Meghalaya

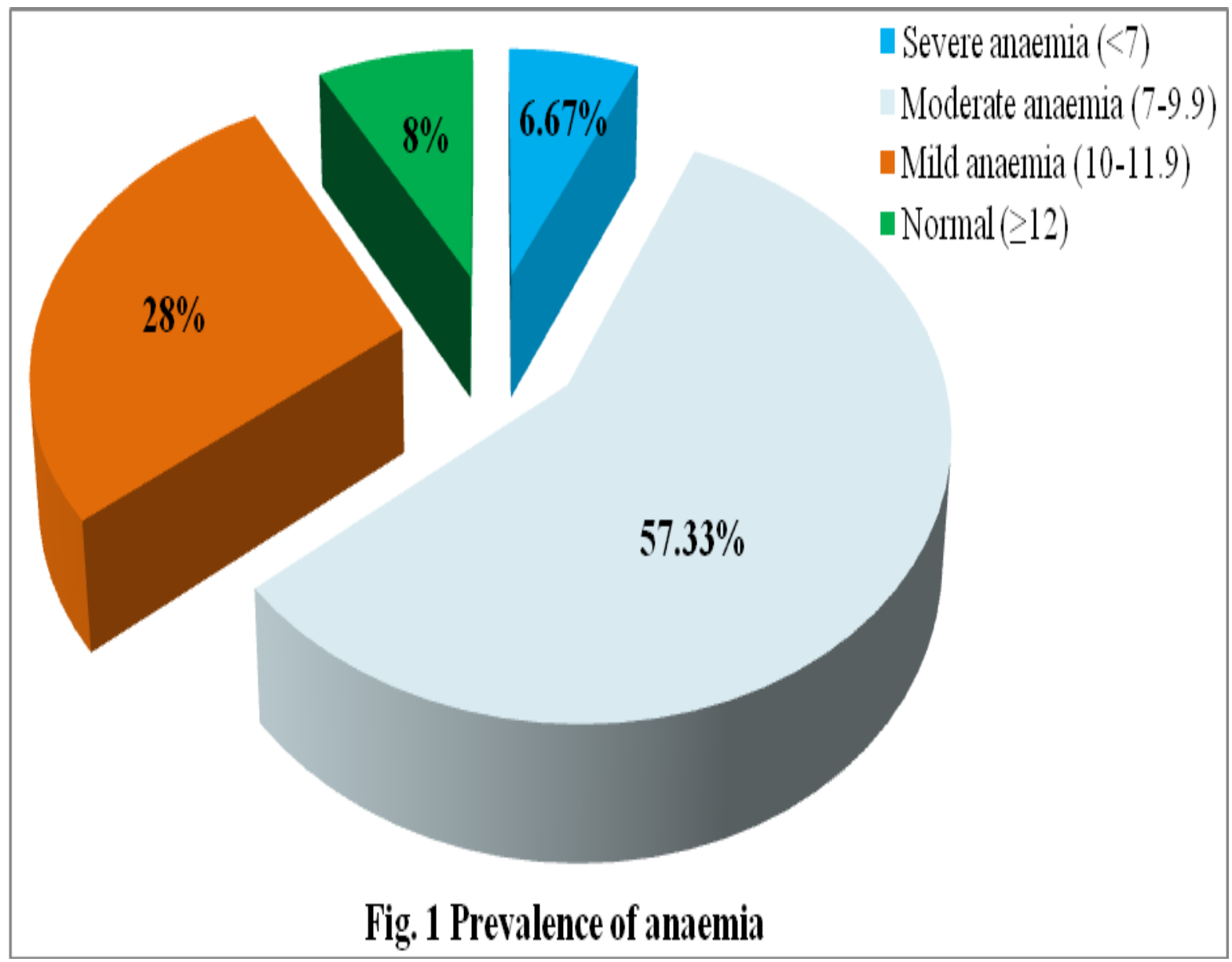



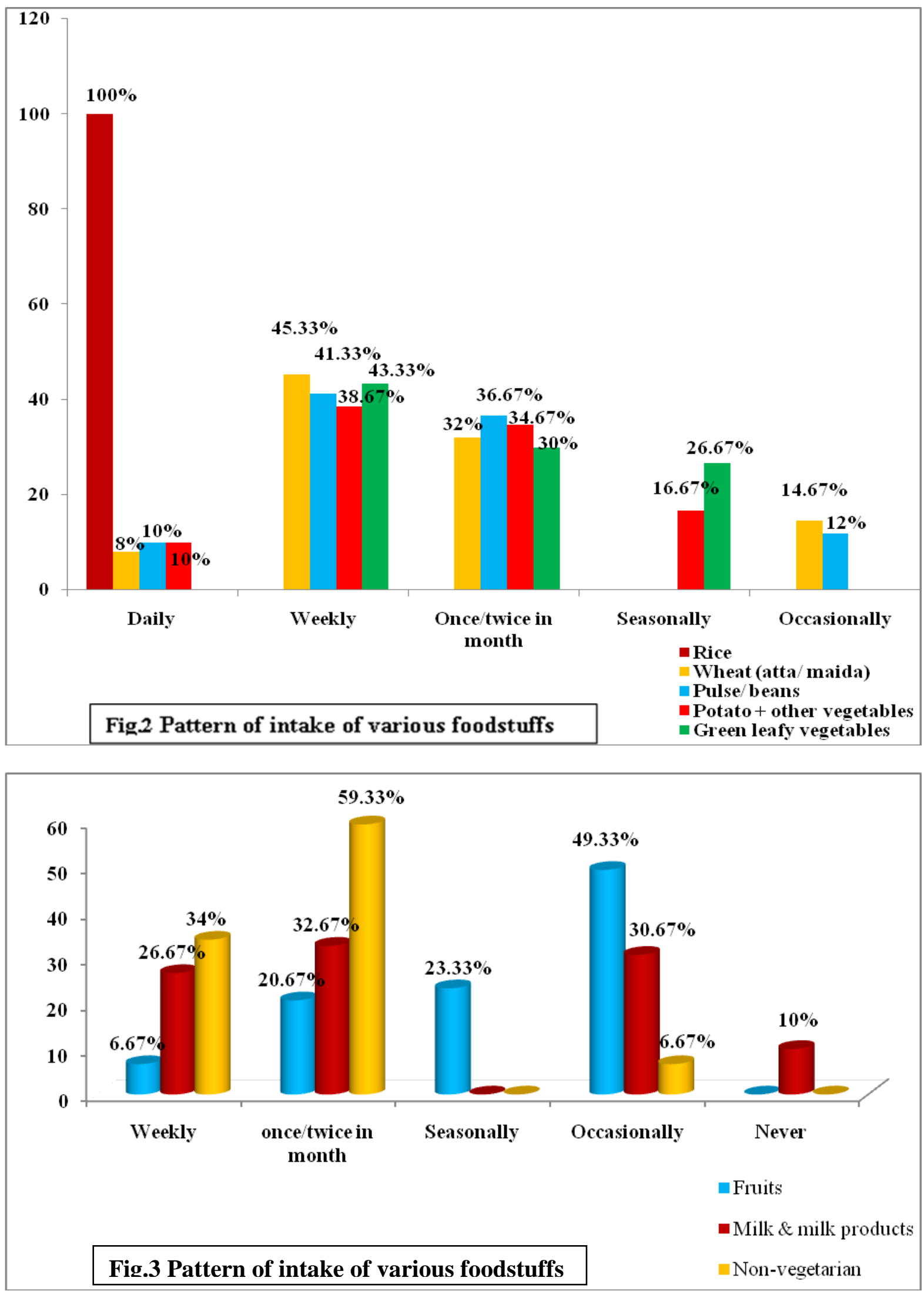
Int.J.Curr.Microbiol.App.Sci (2018) 7(10): 1221-1229

Table.1 Distribution of the subjects according to their nutritional knowledge

\begin{tabular}{|l|}
\hline Particular \\
\hline Carbohydrate \& Fat \\
\hline Gives energy to the body \\
\hline No idea \\
\hline Total \\
\hline
\end{tabular}

\section{Frequency $\quad$ Per Cent}

29

\begin{tabular}{l|l}
121 & 80.67
\end{tabular}

150

100

\section{Protein}

Help in growth and development

No idea

26

17.33

124

82.67

Total

150

100

\section{Iron}

Helps in synthesis of blood

No idea

32

21.33

118

78.67

Total

150

100

\section{Calcium}

Helps in bone development

No idea

33

22

117

78

Total

150

100

\section{Vitamins}

Help in proper body functions

23

15.33

No idea

127

84.67

Total

150

100 


\section{Table.2 Distribution of the subjects according to their nutritional practices}

\begin{tabular}{|c|c|c|c|c|c|}
\hline Particular & Frequency & Per Cent & Particular & Frequency & Per Cent \\
\hline \multicolumn{3}{|l|}{ Filter water } & \multicolumn{3}{|l|}{ Boil water } \\
\hline Yes & 34 & 22.67 & Yes & 121 & 80.67 \\
\hline No & 116 & 77.33 & No & 29 & 19.33 \\
\hline Total & 150 & 100 & & 150 & 100 \\
\hline \multicolumn{3}{|l|}{ Oil used } & \multicolumn{3}{|l|}{ Milk used } \\
\hline Mustard & 99 & 66.0 & Amul taza & 82 & 54.67 \\
\hline Refined & 16 & 10.67 & Sometimes & 38 & 25.33 \\
\hline Both & 35 & 23.33 & Never & 30 & 20.0 \\
\hline Total & 150 & 100 & & 150 & 100 \\
\hline \multicolumn{3}{|l|}{ Washed Rice } & \multicolumn{3}{|l|}{ Washed Dal } \\
\hline Once & 1 & 0.66 & Once & 5 & 3.33 \\
\hline Twice & 110 & 73.33 & Twice & 112 & 74.67 \\
\hline Thrice & 26 & 17.33 & Thrice & 22 & 14.67 \\
\hline$>3$ & 13 & 8.68 & $>3$ & 11 & 7.33 \\
\hline Total & 150 & 100 & & 150 & 100 \\
\hline \multicolumn{3}{|l|}{ Like spicy food } & \multicolumn{3}{|c|}{ Amount of Water drink } \\
\hline Yes & 105 & 70.0 & Two glass & 112 & 74.67 \\
\hline No & 45 & 30.0 & Four glass & 38 & 25.33 \\
\hline Total & 150 & 100 & & 150 & 100 \\
\hline \multicolumn{3}{|l|}{ Reused oil } & \multicolumn{3}{|l|}{ Soda used } \\
\hline Yes & 49 & 32.67 & Everyday & 11 & 7.33 \\
\hline No & 60 & 40.00 & Sometimes & 48 & 32.0 \\
\hline Sometimes & 41 & 27.33 & Never & 91 & 60.67 \\
\hline Total & 150 & 100 & & 150 & 100 \\
\hline \multicolumn{3}{|l|}{ Cooking method } & \multirow{2}{*}{\multicolumn{3}{|c|}{ Tea intake }} \\
\hline Open pan & 65 & 43.33 & & & \\
\hline Open pan \& Pressure cooker & 19 & 12.67 & Once & 18 & 12.0 \\
\hline Open pan \& Rice cooker & 18 & 12.0 & Twice & 121 & 80.67 \\
\hline All the above & 48 & 32.0 & Thrice & 11 & 7.33 \\
\hline Total & 150 & 100 & & 150 & 100 \\
\hline \multicolumn{3}{|l|}{ Vegetables Storage } & \multicolumn{3}{|l|}{ Food allergy } \\
\hline Open space & 106 & 70.67 & Yes & 16 & 10.67 \\
\hline Fridge & 44 & 29.33 & No & 134 & 89.33 \\
\hline Total & 150 & 100 & & 150 & 100 \\
\hline
\end{tabular}

Similarly, Dobhal and Raghuvanshi (2011), Ghosh-Jerath et al., (2016), Rynjah, Anuradha and Thilagamani, (2009), Sreelakshmi et al., (2012), Shrinivasa et al., (2014) had also reported similar findings.

\section{Pattern of various foodstuffs intake}

The figure 2 and 3 clearly depicts the pattern of various foodstuffs intake of the respondents. Rice is their staple diet 
consumed twice daily. The study revealed that the subjects' consumption of various foodstuffs was inadequate and not satisfactory. The consumption of cereals, pulses, milk and milk products, fruits were all inadequate.

The study subjects gave lesser importance to the consumption of milk and milk products and fruits. Daily consumption of milk and milk products was not observed among the subjects. Only 26.67 per cent consumed milk and milk products weekly. Almost half $(49.33 \%)$ of the subjects consumed fruits occasionally. Similarly, Nanda and Dhar (2017) Kaur and Kaur (2011), Ghosh-Jerath et al., (2016), Rao et al., (2006) and Shadap and Pala (2017) reported similar findings.

This study depicted a clear picture of prevalence of anaemia, intake pattern and nutritional knowledge and practices among the tribal females of reproductive age group of Meghalaya. The study enlightened the consumption pattern of the participants. It revealed that intake pattern of various foodstuff and nutritional knowledge and practices of the selected tribal women were not satisfactory up to the standard of living.

This could increase the risk of under nutrition as well as nutrient deficiency diseases because nutritional status is directly connected with the dietary habits. An appropriate step is urgently required to provide nutritional awareness regarding nutritional practices to the tribal women to improve their dietary pattern and nutritional knowledge and practices of this scheduled tribe community.

\section{Acknowledgment}

We acknowledge the Department of Food Science and Nutrition, College of Home Science, CAU (Imphal), Tura, Meghalaya.

\section{References}

Chauhan, S. K., Jungari, S., and Chauhan, B.G. (2015). Burden of Anaemia among Women in Jharkhand, India: Does Lifestyle Behaviour Matters? J. Nutri. Health, 1 (2): 1-9.

Choudhary, M., and Dashora, R. (2015). Effect of nutritional status on prevalence of anaemia among females. Food sci. Res. J., 6 (1): 1-7.

Dabral, M., and kothiyal, P. (2016). Prevalence of anemia among reproductive age group tribal women in Uttarakhand, India. Indian J. Pharm. Sc. Res., 6 (1):47-50.

Devi, T. A., and Sindhuja, S., 2015. Nutritional status and knowledge, life style and dietary practices of tribal adult women. International Journal of Recent Scientific Research. 6 (6): 4449-4452.

Ghosh-Jerath, S., Singh, A., Magsumbol, M.S., Lyngdoh, T., Kamboj, P., and Goldberg, G., 2016. Contribution of indigenous foods towards nutrient intakes and nutritional status of women in the Santhal tribal community of Jarkhand, India. Public Health Nutrition. 19 (12): 2256-2267.

Joshi, P., Joseph, D., Bajpai, P., Manoria, P., Joshi, P., Yadav, V., Dagore, H., and Jha, R.K. (2013). Prevalence of Anemia among the General Population of Malwa (M.P.), Indian J. Evo. Med. Dent. Sc., 2 (1): 46-51.

Joshi, S., and Singh, V., 2015. Assessment of food related habits and customs of Bhil tribe of Udaipur district, Rajasthan. Food science Research Journal. 6 (2): 333-340.

Kaur, I.P., and Kaur, S. (2011). A comparison of nutritional profile and prevalence of anemia among rural girls and boys. $J$. Exercise Sc. Physioth., 7 (1): 11-18.

Kamath, R., Majeed, J. A., Chandrasekaran, V., and Pattanshetty, M. S. (2013). 
Prevalence of Anemia among Tribal Women of Reproductive Age in Udupi Taluk, Karnataka. J. Family Med. Prim. Care, 2 (4): 345-348.

Nanda, S., and Dhar, R. N., 2017. A study on nutritional status of adolescent girls of Dongria Kondh tribe. International Journal of Community Medicine and Public Health. 4 (5): 1573-1576.

Rao, V.G., Sugunan, A.P., Murhekar, M.V., and Sehgal, S.C., 2006. Malnutrition and high childhood mortality among the Onge tribe of the Andaman and Nicobar Islands Public Health Nutrition. 9 (1): 19-25.

Rynjah, R., Anuradha, V., and Thilagamani, S., 2009. Nutritional status of tobacco users among the khasi tribes in Meghalaya. Indian Journal of Nutrition and Dietetics. 46 (9): 357-363.

Shadap, A.M.W. K., and Pala, V., 2017. Nutritional Intake and Consumption Pattern in the States of Himachal
Pradesh and Meghalaya. The NEHU Journal. 15 (2):15-28.

Shrinivasa, B. M., Philip, R. R., Krishnapali, V. K., Suraj, A., and Sreelakshmi, P. R., 2014. Prevalence of anemia among tribal women of reproductive age-group in Wayanad district of Kerala. International Journal of Health and Allied Sciences. 3 (2): 120-124.

Siddiqui, S., Bhatnagar, V., and Lakhawat, S. (2016). Nutritional status assessment of Ghosi Gujjar women of Ajmer district with special reference to anemia. Int. J. Home Sc., 2 (3): 159-161.

Sreelakshmi, P.R., Vijayakumar, K., Anish, T.S., Shrinivasa, B.M., Sheela, S., Abraham, A., and Mendez, A., 2012. Anaemia and body mass index of nonpregnant tribal women of reproductive age group in Palakkad District of Kerala, India. Indian Journal of Preventive and Social Medicine. 43 (1): $35-41$.

\section{How to cite this article:}

Elvina Shongsir Monsang and Namita Singh. 2018. Prevalence of Anaemia and Nutritional Knowledge among Tribal Women of Reproductive Age Group of Meghalaya, India. Int.J.Curr.Microbiol.App.Sci. 7(10): 1221-1229. doi: https://doi.org/10.20546/ijcmas.2018.710.136 